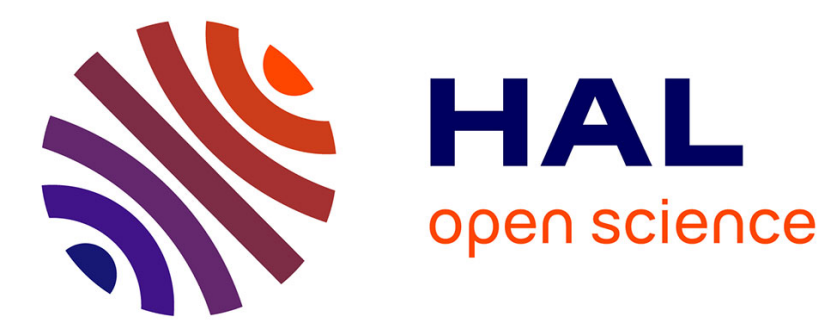

\title{
Perfluorinated substances and telomeres in an Arctic seabird: Cross-sectional and longitudinal approaches
} Pierre Blévin, Frédéric Angelier, Sabrina Tartu, Paco Bustamante, Dorte Herzke, Børge Moe, Claus Bech, Geir Wing Gabrielsen, Jan Ove Bustnes, Olivier Chastel

\section{To cite this version:}

Pierre Blévin, Frédéric Angelier, Sabrina Tartu, Paco Bustamante, Dorte Herzke, et al.. Perfluorinated substances and telomeres in an Arctic seabird: Cross-sectional and longitudinal approaches. Environmental Pollution, 2017, 230, pp.360-367. 10.1016/j.envpol.2017.06.060 . hal-01683154

\section{HAL Id: hal-01683154 https://hal.science/hal-01683154}

Submitted on 12 Jan 2018

HAL is a multi-disciplinary open access archive for the deposit and dissemination of scientific research documents, whether they are published or not. The documents may come from teaching and research institutions in France or abroad, or from public or private research centers.
L'archive ouverte pluridisciplinaire HAL, est destinée au dépôt et à la diffusion de documents scientifiques de niveau recherche, publiés ou non, émanant des établissements d'enseignement et de recherche français ou étrangers, des laboratoires publics ou privés. 


\section{Perfluorinated substances and telomeres in an Arctic seabird: Cross-sectional and longitudinal approaches}

Pierre Blévin $^{\mathrm{a}^{*}}$, Frédéric Angelier ${ }^{\mathrm{a}}$, Sabrina Tartu ${ }^{\mathrm{a}}$, Paco Bustamante ${ }^{\mathrm{b}}$, Dorte Herzke ${ }^{\mathrm{c}}$, Børge Moe $^{\mathrm{d}}$, Claus Bech ${ }^{\mathrm{e}}$, Geir Wing Gabrielsen ${ }^{\mathrm{f}}$, Jan Ove Bustnes ${ }^{\mathrm{g}}$, Olivier Chastel ${ }^{\mathrm{a}}$

${ }^{\text {a }}$ Centre d'Etudes Biologiques de Chizé (CEBC), UMR 7372 - CNRS \& Université de La Rochelle, 79360 Villiers-en-Bois, France

${ }^{\mathrm{b}}$ Littoral Environnement et Sociétés (LIENSs), UMR 7266 - CNRS \& Université de La Rochelle, 2 rue Olympe de Gouges, 17000 La Rochelle, France

${ }^{\mathrm{c}}$ Norwegian Institute for Air Research, NILU, Fram Centre, NO-9296 Troms $\emptyset$, Norway

d Norwegian Institute for Nature Research, NINA, Høgskoleringen 9, NO-7034 Trondheim, Norway

${ }^{\mathrm{e}}$ Department of Biology, Norwegian University of Science and Technology, NO-7491

Trondheim, Norway

${ }^{\mathrm{f}}$ Norwegian Polar Research Institute, Fram centre, NO-9296 Troms $\varnothing$, Norway

g Norwegian Institute for Nature Research, NINA, Fram centre, NO-9296 Troms $\varnothing$, Norway

\section{Corresponding author}

Pierre Blévin

Centre d'Etudes Biologiques de Chizé, CNRS UMR 7372

79360 Villiers-en-Bois, France

E-mail address: blevin.pierre@gmail.com 
Abstract: Telomeres are non-coding DNA repeats located at the termini of eukaryotic chromosomes, regulated by dynamic processes balancing shortening and maintenance. Despite a mechanism to slow-down telomere shortening, cell division leads to progressive attrition of chromosomes, leading to the onset of cellular senescence or apoptosis. However, telomere restoration based on telomerase activity is the primary mechanism for telomere maintenance. Telomere length is associated to health and survival and can be impacted by a broad panel of environmental factors. However, the effect of contaminants on telomeres is poorly known for living organisms. The aim of this study was to investigate relationships between some polyand perfluoroalkyl substances (PFASs), body condition and telomere length by using both a cross-sectional and longitudinal approach in adult breeding Black-legged kittiwakes (Rissa tridactyla) from Svalbard. First, we examined the associations between absolute telomere length and PFASs contamination in a given year (cross-sectional approach). Second, we investigated the relationships between telomere dynamics and PFASs contamination within a two years' time frame (longitudinal approach). Our results did not show any significant relationships of PFASs and body condition with absolute telomere length in a given year. Surprisingly, we found a positive and significant relationship between PFASs and telomere dynamics in both sexes with elongated telomere in birds bearing the highest concentrations of PFASs. Our study underlines (i) the need to investigate PFAS effects on telomere dynamics with a longitudinal approach and (ii) a potential positive effect of these contaminants on telomere length, with the most contaminated birds showing the slowest rate of telomere shortening or even displaying elongated ones. Our study is the first to report a relationship between PFASs and telomere length in free-living vertebrates. A possible underlying mechanism and other potential confounding factors are discussed.

Keywords: Organic contaminants; PFASs; Black-legged kittiwake; Svalbard; DNA 


\section{Introduction}

Halogenated contaminants such as the poly- and perfluoroalkyl substances (PFASs) are synthetically manufactured chemicals produced since the 1950s. They are mainly used as surfactants and water repellents in numerous industrial and commercial applications because of their unique hydrophobic and oleophobic properties (e.g. fire-fighting foam, waterproof clothing, non-stick coating and impregnation agent for carpets, papers and textiles; Kissa, 2001). PFASs are either released in the environment by direct discharge (“direct emissions”) or result from the degradation of precursor compounds ("indirect emissions"; Butt et al., 2010). PFASs are carbon chains varying in length, where hydrogen is replaced by fluorine atoms. Chemical bonds between carbon and fluorine atoms are very strong which make the PFASs thermally and chemically stable, resistant to degradation, and thus extremely persistent in the environment (Key et al., 1997; Muir and de Wit, 2010). Because of atmospheric long-range transport and oceanic currents, some PFASs reach remote areas such as the Arctic marine ecosystem, where they are preferentially deposited because of cold climate (AMAP, 2004; reviewed in Butt et al., 2010; Ellis et al., 2004; Giesy and Kannan, 2001; Prevedouros et al., 2006). The Arctic is therefore considered as a sink for environmental contaminants such as the PFASs. Specifically the perfluoroalkyl carboxylic acids (PFCAs), seem to increase in Arctic marine biota, contrary to the PFOS, a compound that belongs to sulfonic acids (PFSAs) which appears to decline since mid-2000s, after the phase-out by the US company $3 \mathrm{M}$ (reviewed in AMAP, 2016; Braune and Letcher, 2013; reviewed in Butt et al., 2010; Rotander et al., 2012; Wania, 2003).

Once deposited in the marine ecosystem, PFASs enter in the food chain with phytoplankton uptake, bioaccumulate in living organisms via food intake and increase with the trophic position due to biomagnification (Fang et al., 2014; Haukås et al., 2007; Kannan et al., 2005; Kelly et al., 2009; Tomy et al., 2004). There is now strong evidence that (i) PFASs accumulate and 
persist in protein-rich compartments (e.g. blood, liver, kidneys) and (ii) PFASs biomagnification is enhanced as the carbon chain length increases (Aas et al., 2014; reviewed in Butt et al., 2010; Conder et al., 2008; Kelly et al., 2009; Verreault et al., 2005). Indeed, PFAS profiles in liver and/or plasma of four Arctic seabird species, the Thick-billed murres (Uria lomvia), the Northern fulmar (Fulmarus glacialis), the Glaucous gull (Larus hyperboreus) and the Black-legged kittiwake (Rissa tridactyla), were dominated by long-chained PFCAs (Butt et al., 2007; Tartu et al., 2014; Verreault et al., 2005). As top predators, Arctic seabirds are exposed to relatively high concentrations of environmental contaminants; they are thus considered as extremely pertinent biological indicators to investigate the potential hazardous effects of PFASs on wildlife. To date, our knowledge about effects of PFASs exposure is limited (DeWitt, 2015; Jensen and Leffers, 2008; Lau et al., 2007), especially for free-living animals, although few studies have reported interactions between PFASs and physiology. For instance, several studies conducted on fishes and birds reported high concentrations of thyroid hormones and low levels of stress hormones in most PFASs contaminated individuals (Braune et al., 2011; Liu et al., 2011; Nøst et al., 2012; Tartu et al., 2014). More importantly, it has been suggested that PFASs could decrease the hatching success in two avian species, the BlackLegged kittiwake and the Tree swallow (Tachycineta bicolor; Custer et al., 2012; Tartu et al., 2014; but see also Bustnes et al., 2008). Further investigations focusing on wildlife and including more physiological and fitness traits are needed to better assess the impact of these contaminants on animals living in natural ecosystems (Kannan, 2011; Lau et al., 2007). Among potential physiological investigations to be conducted for a better assessment of the toxicological consequences of PFASs exposure, are the telomeres. Telomeres are non-coding DNA repeats located at the termini of eukaryotic chromosomes and play a key role in ensuring the genomic stability (Blackburn, 1991; Monaghan and Haussmann, 2006). Because the DNA polymerase protein complex is unable to fully achieve the chromosomes replication during 
mitosis (i.e. end-replication problem), telomere length progressively shortens through life as a consequence of repeated cell divisions (Blackburn, 1991; Olovnikov, 1996; Sedivy, 1998). When telomere length is too short, cell division can damage coding DNA inducing cellular senescence or apoptosis (Blasco, 2007; Campisi et al., 2001; Harley et al., 1990; Olovnikov, 1996). Importantly, telomere length and telomere dynamics have been shown to be reliable predictors of longevity and survival in captive and wild vertebrates (Asghar et al., 2015; Barrett et al., 2013; Bauch et al., 2014; Bize et al., 2009; Boonekamp et al., 2014; Haussmann et al., 2005; Heidinger et al., 2012; Fairlie et al., 2016; Foote et al., 2010; Salomons et al., 2009). Moreover, recent studies have demonstrated that the rate of telomere shortening varies to a great extent between individuals. Indeed, telomere shortening has been shown to be accelerated by the occurrence of a wide range of environmental stressors (Angelier et al., 2013; Epel et al., 2004; Hau et al., 2015; Meillère et al., 2015; Mizutani et al., 2013; Salmon et al., 2016; Young et al., 2013) including heavy metals and persistent organic contaminants (Blévin et al., 2016; Stauffer et al., 2017). However, there is still very few information regarding the effects of contaminants on absolute telomere length in free-living animals and no studies have been conducted so far on telomere dynamics, with a longitudinal approach. To the best of our knowledge, a single study has investigated the influence of PFASs on absolute telomere length (with a cross-sectional approach) in free-living birds but did not report any significant relationships (Sletten et al., 2016). Because of this link with survival and environmental stressors, measuring the effect of specific compounds on telomere length and telomere dynamics appear promising to better assess their impact on wildlife (Bateson, 2015).

In Svalbard, Black-legged kittiwakes (Rissa tridactyla, hereafter "kittiwakes"), are exposed to a complex cocktail of organic contaminants and heavy metals which are known to correlate with impaired individual fitness and population dynamics (Goutte et al., 2015; Tartu et al., 2013, 2014, 2015, 2016). Kittiwakes are thus potentially sensitive to a broad mixture of 
contaminants with many possible additive, synergistic, as well as antagonistic effects. The aim of the present study is to investigate the relationships between several measured PFASs (11 PFCAs and 3 PFSAs), body condition and telomere length by using both a cross-sectional and longitudinal approach in adult breeding kittiwakes from Svalbard. First, we examined the relationships between PFASs contamination and absolute telomere length within a given year (cross-sectional approach in 2012). Second, we investigated the associations between PFASs contamination in 2012 and telomere dynamics by sampling the same kittiwakes twice over a time frame of two years (longitudinal approach, between 2012 and 2014). Predictions are challenging since the impact of PFASs on the survival rate of free ranging vertebrates remains undocumented with the exception of a study conducted on the glaucous gull where no relationships between PFASs and adult returning rate were found (Bustnes et al., 2008). However, since PFASs are expected to be detrimental for living organisms and appear to disrupt several physiological processes (e.g. endocrine disruption) in wildlife, as well as in laboratory animals (Austin et al., 2003; reviewed in DeWitt, 2015; reviewed in Lau et al., 2007; Liu et al., 2011), we predict that a high PFASs contamination will be associated with a rapid rate of telomere shortening (longitudinal approach), and thus, with short telomeres (cross-sectional approach).

\section{Material and methods}

Fieldwork was conducted in 2012 , from $12^{\text {th }}$ to $27^{\text {th }}$ July and in 2014 , from $26^{\text {th }}$ June to $20^{\text {th }}$ July, within a colony of black-legged kittiwakes at Kongsfjorden ( $\left.78^{\circ} 54^{\prime} \mathrm{N} ; 12^{\circ} 13^{\prime} \mathrm{E}\right)$, Svalbard. In 2012, 44 breeding adults (22 males and 22 females) were trapped while sitting on their nest with a loop at the end of long pole during the chick rearing period. All birds were assigned with a unique three-letter code fixed to the bird's tarsus. We collected a $2 \mathrm{~mL}$ blood sample from the alar vein using a heparinized syringe and a 25-gauge needle to assess PFAS 
concentrations, measure telomere length and determine gender. Then, skull length (head p bill) was measured with an accuracy of $0.1 \mathrm{~mm}$ using a calliper and birds were finally weighted to the nearest $2 \mathrm{~g}$ with a Pesola spring balance. In 2014, 17 birds (12 males and 5 females) out of the 44 kittiwakes caught in 2012 were recaptured after identification at a distance using a telescope. Indeed, in that colony the adult annual survival rate is $85 \%$ and the percentage of birds successfully reaching the chick rearing is about 75\% (Goutte et al., 2015). Moreover, some birds were not possible to catch. After capture, these birds were blood sampled to assess PFAS concentrations (only 6 birds) and measure telomere length. Blood samples were stored on ice in the field. Plasma and red blood cells, obtained after centrifugation were kept frozen at $-20^{\circ} \mathrm{C}$ before subsequent lab work.

Telomere analysis was performed from red blood cells collected in $2012(\mathrm{n}=38 ; 22$ males and 16 females) and in $2014(\mathrm{n}=17 ; 12$ males and 5 females $)$ at the Centre d'Etudes Biologiques de Chizé in France (CEBC). Indeed, over the 44 individuals caught in total in 2012, telomeres analysis was conducted on 38 individuals since not enough blood was left for 4 females. Telomere length was measured with the telomere restriction fragment method (TRF) by Southern blot and using the TeloTAGG Telomere Length Assay (Roche, Mannheim, Germany) as previously described and with minor modifications (Foote et al., 2010; Kimura et al., 2010a). Specifically, we have adjusted the quantity of DNA to allow a correct visualisation of the DNA signal on the gels. Briefly, samples were digested with proteinase K and DNA was extracted from red blood cells using the DNeasy blood and tissue kit (Qiagen). Gel electrophoresis and optical density spectrophotometry were used to check for DNA quality. Preliminary tests have been conducted to determine the optimal amount of DNA to be used and, for each sample, 0.7 mg of DNA was digested with the restriction enzymes HinfI and RsaI for $16 \mathrm{~h}$ at $37^{\circ} \mathrm{C}$. Digested DNA samples were then separated with a pulse-field gel electrophoresis (Bio-Rad) on a $0.8 \%$ agarose gel. Samples were randomly assigned to a gel except those used to assess telomere 
length dynamics which were treated in the same gel. At total, all samples were run in 4 gels. Internal controls were run on each gel to measure inter-gel variations and each gel was run at $3.0 \mathrm{~V} / \mathrm{cm}$ with an initial switch time of $0.5 \mathrm{~s}$ to a final switch time of $7 \mathrm{~s}$ for $14 \mathrm{~h}$. Following that step, the gel was depurinated and denaturated in an alkaline solution. The gel was then neutralized and DNA was transferred onto a nitrocellulose membrane by Southern blot (Hybond $\mathrm{N}+$, Amersham Life Science, Amersham, UK). The membrane was placed in an incubator and dried at $120{ }^{\circ} \mathrm{C}$ for $20 \mathrm{~min}$ in order to fix the DNA. The DNA was then hybridized with a digoxigenin-labeled probe specific for telomeric sequences and incubated with antidigoxigeninspecific antibody before visualization with a Chemidoc (Bio Rad). Telomere length was then analyzed using ImageJ software and measured from telomere smear densities. Lane-specific background was subtracted from each density and telomere length (mean value) was then calculated within a window of $5 \mathrm{e} 30 \mathrm{~kb}$ that includes the whole smear (Nussey et al., 2014). Inter-gel CV was 1.40. Telomere dynamics relates to the difference of telomere length between 2014 and 2012. Molecular sexing was conducted at the CEBC, from red blood cells of samples collected in 2012 (22 males and 22 females) by polymerase chain reaction (PCR) amplification of part of two highly conserved genes (CHD) present on sexual chromosomes following Fridolfsson and Ellegren (1999).

PFAS concentrations were determined from plasma samples collected in 2012 ( $\mathrm{n}=44 ; 22$ males and 22 females) and 2014 ( $n=6 ; 4$ males and 2 females) at the Norwegian Institute for Air Research (NILU) in Tromsø, Norway. We searched for 14 PFASs: perfluorobutanesulfonate (PFBS), perfluorohexanesulfonate (PFHxS), linear perfluorooctanesulfonate (PFOSlin), perfluorobutanoate (PFBA), perfluoropentanoate (PFPA), perfluorohexanoate (PFHxA), perfluoroheptanoate (PFHpA), perfluorooctanoate (PFOA), perfluorononanoate (PFNA), perfluorodecanoate (PFDcA), perfluoroundecanoate (PFUnA), perfluorododecanoate (PFDoA), perfluorotridecanoate (PFTrA), and perfluorotetradecanoate (PFTeA). Compounds 
not detected in $100 \%$ of the samples were not included in statistical analyses. Thereby, those remaining for further investigations were PFOSlin, PFNA, PFDcA, PFUnA, PFDoA, and PFTrA. Briefly, a sample $(0.5 \mathrm{~mL})$ spiked with internal standards was extracted in acetonitrile $(1 \mathrm{~mL})$ by repeated sonication and vortexing. The supernatant was cleaned-up using ENVICarb graphitized carbon absorbent and glacial acetic acid. Extracts were analyzed by UPLC/MS/MS. Recovery of the internal standards ranged between $50 \%$ and $120 \%$ and the deviation of the target concentrations in the standard reference materials (NIST Human serum 1958) were within the laboratory's accepted range $(76-105 \% ; n=3)$. All blanks concentrations were below the instrument detection limits. Limit of detection of each compound is given in Table 1.

Statistical analyses were performed using R 3.3.1 (R Core Team, 2016). Data exploration was conducted mainly following Zuur et al. (2010). We first performed a principal component analysis (PCA; "Ade4 package") with individual PFASs in order to reduce the number of explanatory variables. We preferred this method instead of examining each contaminant separately because, (i) PFAS compounds are highly correlated with each other and (ii) it considerably decreases the number of statistical models since testing many models can potentially increase the type I error. The appropriate use of PCA was tested and confirmed through the Kaiser-Mayer-Olkin measure of sampling adequacy $(\mathrm{K}-\mathrm{M}-\mathrm{O}=0.74)$ and the Bartlett's test of sphericity ( $\mathrm{p}<0.001$ ). The number of significant principal components was selected according to the Kaiser criterion (i.e. eigenvalue higher than 1; Kaiser,1960). The PCA resulted in one component (PC1), explaining $71 \%$ of the total variance and mainly influenced by high concentrations of PFDcA (factor loading: 0.45), PFUnA (0.45), PFOSlin (0.44), PFDoA (0.44) and to a minor extent PFTrA (0.33) and PFNA (0.32). Body condition was calculated with the residuals of the regression of body mass against skull length. The influence of contaminants and body condition in 2012 on absolute telomere length in 2012 and telomere 
length dynamics were investigated using linear models. Thus, PC1, body condition and sex were considered as explanatory variables while telomere length in 2012 and telomere dynamics were defined as response variables. Because PFAS concentrations in 2012 were different between sexes (Table 1), including the factor "sex" with the PFASs variable in the same model could induce multicollinearity problems and lead to biased results (Graham, 2003). However, it has been proposed to use the variance inflation factor (VIF) as a statistical tool to assess the extent of dependence between explanatory variables. Several studies suggested that below a value of 10, dependence is no longer a major issue (Chatterjee and Price, 1991; Neter et al., 1996), but a more stringent approach is to consider VIF < 3 (Zuur et al., 2009). Because males were more contaminated than females, VIF was then calculated between PC1 and the factor "sex" to ensure that these explanatory variables met independence (VIF = 1.16; calculated with “AED package" developed by Zuur et al., 2009). Biologically relevant models were constructed with PC1, body condition, sex and interactions of PC1 and body condition with sex as predictor variables. The best models were then selected with the bias adjusted Akaike's Information Criterion (AICc), defined as a bias adjustment for small-sample size (Burnham and Anderson, 2004). If AICc values differ by more than 2, the lowest AICc is the more accurate, whereas if AICc differ by less than two, models are considered as fairly similar in their ability to describe the data. Additionally, the Akaike weight $(W i)$ was estimated and can be interpreted as approximate probabilities that the model $i$ is the best one to predict the data, given the candidate set of models (Burnham and Anderson, 2004; Johnson and Omland, 2004). We finally performed diagnostic plots and Shapiro normality tests on residuals to check if the data sufficiently met the linear model assumptions (Zuur et al., 2009). Data were log-transformed when testing for sex differences of PFAS concentrations and when investigating correlations between each PFAS compounds. A significance level of $a<0.05$ was used for all tests. 


\section{Results}

\subsection{PFAS concentrations}

Plasma PFAS mean concentrations \pm standard errors for chick-rearing adult kittiwakes in 2012 are listed in Table 1. Linear models to test gender-related differences indicated that all PFASs except PFNA and PFTrA significantly differed between sexes, with males having higher concentrations than females. Such sex-related differences of PFAS concentrations could be attributed either to the ability of females to transfer elevated amounts of contaminants into their eggs (Gebbink and Letcher, 2012) and/or to sexual differences regarding foraging ecology, with males feeding at higher trophic levels or in more contaminated areas than females. All PFASs (logtransformed) were highly and positively correlated with each other (Pearson correlations: $0.49 \leq \mathrm{r} \leq 0.93$, all $\mathrm{p}$-values $<0.001 ; \mathrm{n}=44)$, indicating similar exposure routes. Finally, PFAS concentrations seem to be repeatable (from 2012 to 2014) within the same individuals ( $r=0.59$, $\mathrm{n}=6$; calculated from the repeatability equation developed by Lessells and Boag, 1987). In other words, an individual with relatively high levels of PFASs in 2012 will also show relatively high levels of PFASs in 2014. However, the sample size is low $(n=6)$ and further studies conducted on a larger sample size would enable to confirm this statement.

\subsection{Relationships between contaminants, body condition and telomere length}

The model selection to explain absolute telomere length based on PFAS concentrations (PC1) and body condition in 2012 for male and female adult kittiwakes is presented in Table 2. Among the set of candidate models, the null model (parameterized with an intercept only) showed the best fit to the data. None of the other candidate models including sex, PC1 or body condition (as well as the interaction terms with sex) was better than the null model. These variables were 
therefore not good predictors of absolute telomere length, and PFAS concentrations in 2012 do not appear as good explanatory variables of absolute telomere length in 2012 (PC1, slope: a = 0.06; $\mathrm{p}=0.443$; Fig. 1)

The model selection to explain telomere dynamics between 2012 and 2014 based on PFAS concentrations (PC1) and body condition in 2012 for male and female adult kittiwakes is presented in Table 3. Among the set of candidate models, the model including PC1 best fitted the data $(\triangle \mathrm{AICc}=2.8) . \mathrm{PC} 1$ was significantly and positively related to telomere dynamics (slope: $\mathrm{a}=0.17, \mathrm{p}=0.026$; Fig. 2). In other words, the most PFASs contaminated individuals in 2012 were those showing the slowest rate of telomere shortening from 2012 to 2014 . Body condition and the gender were not were not considered as good predictors of telomere dynamics (Table 3).

\section{Discussion}

We observed no relationships between PFASs, body condition and absolute telomere length when analyzing only one year (cross-sectional approach in 2012). However, the results from the longitudinal approach indicated PFASs in 2012 as the best predictor of telomere dynamics. There was a significant and positive relationship between PFAS plasma concentrations in 2012 and telomere dynamics with the most PFASs-contaminated individuals showing the slowest rate of telomere shortening from 2012 to 2014. Additionally, among the most PFAS contaminated birds, 4 individuals displayed elongated telomeres from 2012 to 2014. This suggests some potential positive effects of PFASs contamination on telomeres. Considering the discrepancy in the findings between the two approaches, our study highlights the need to investigate the effects of PFASs on telomere dynamics with a longitudinal approach, rather than simply measuring absolute telomere length in a single snapshot. In vertebrates, most of telomere 
shortening occurs early in life, during growth and developmental stages and this rate of earlylife shortening varies to a great extent between individuals (Boonekamp et al., 2014; Hall et al., 2004; Foote et al., 2010; Frenck et al., 1998; Friedrich et al., 2001; Rattiste et al., 2015; Salomons et al., 2009; Zeichner et al., 1999). In addition, telomere length can also be affected later in life, in adults, by variation in stressful experiences (Angelier et al., 2013; Epel et al., 2004; Hau et al., 2015; Mizutani et al., 2013; Young et al., 2013). As a result, there is probably a large inter-individual variability in telomere length in adult kittiwakes and this variability may result from several factors that were not taken into account in our analyses (e.g. age, environmental stressors, etc.). This large inter-individual variability can certainly blur the potential effect of PFASs contamination on telomere length when using a cross-sectional approach, possibly explaining why we were not able to detect any correlations between PFASs contamination and absolute telomere length in 2012. Because PFASs contamination appears quite repeatable over two years within the same individual, the longitudinal approach allows us to relate such PFASs contamination in 2012 with telomere dynamics.

Only three studies have studied the associations between contaminants and telomere length in free-ranging vertebrates (Blévin et al., 2016; Sletten et al., 2016; Stauffer et al., 2017). Thus, this work contributes at filling the gap of knowledge about the potential effects of environmental contaminants on telomere length in wildlife. Contrary to our results from the longitudinal approach, PFASs did not predict telomere length in white-tailed eagle (Haliaeetus albicilla) chicks (Sletten et al., 2016). However, this study did not investigate the relationships between contaminants and telomere dynamics, but rather used a cross-sectional approach (i.e. a single measure of telomere length). This could potentially explain the discrepancy between the results of the two studies. Another potential explanation would rely on the difference of concentrations of contaminants between eagle chicks and kittiwake adults but this statement does not seem relevant here. While PFOSlin concentration in kittiwakes (9 $884 \pm 462$ pg/g ww) 
were on average 4 times lower than those in eagle chicks (40 $914 \pm 5746$ pg/g ww), PFUnA concentration in kittiwakes (10 $746 \pm 509 \mathrm{pg} / \mathrm{g} \mathrm{ww})$ were on average 2 times higher than those in eagle chicks (5 $609 \pm 525 \mathrm{pg} / \mathrm{g} \mathrm{ww}$ ). Finally, a recent study conducted on the same kittiwake population showed a negative relationship between telomere length and oxychlordane (Blévin et al., 2016), a metabolite of an organochlorine pesticide considered as very toxic for wildlife (Bustnes, 2006; Erikstad et al., 2013; Goutte et al., 2015). Organochlorines and PFASs are structurally opposed, with organochlorines being lipophilic (Findlay and DeFreitas, 1971) and PFASs having a high affinity with proteins (Heuvel et al., 1992). Moreover, kittiwakes are exposed to an additional mixture of chemicals, which are not included in this study and which could act on telomere length (Stauffer et al., 2017). Consequently, further investigations focusing on various chemicals, structurally different, may enable to clarify such contrasted results.

Telomere length adjustment is dynamic with both shortening and maintenance events. Despite a mechanism to slow-down telomere shortening, the end-replication problem leads to progressive attrition of chromosomes, leading to the onset of cellular senescence or apoptosis (Blasco, 2007; Campisi et al., 2001; Harley et al., 1990; Olovnikov, 1996). However, telomere restoration based on telomerase activity, an enzyme adding new telomeric sequences onto the ends of chromosomes at each DNA replication, has been shown to be the primary mechanism for telomere maintenance and genomic integrity (Blackburn, 1991, 2005; Greider and Blackburn, 1985). Telomerase is variably active in several somatic and post-somatic tissues throughout the lifespan of long-lived seabirds (Haussmann et al., 2007). This latest study highlighted the very high activity of telomerase in bone marrow during the whole lifespan of two seabird species, the Common tern (Sterna hirundo) and the Leach's storm petrel (Oceanodroma leucorhoa; Haussmann et al., 2007). The authors stated that "telomerase activity in bone marrow may be associated with the rate of erythrocyte telomere shortening; birds with 
lower rates of telomere shortening and longer lifespans have higher bone marrow telomerase activity throughout life". Indeed, all circulating erythrocytes in birds are produced by the hematopoietic stem cells of the bone marrow (Sturkie and Griminger, 1976), and telomere length measured in erythrocytes appear to mirror the telomere length of stem cells in bone marrow (Kimura et al., 2010b; Vaziri et al., 1994; but see Reichert et al., 2013). Thus, which underlying mechanisms could induce a disruption of telomerase activity and how can it be related to PFASs contamination? Indeed, several correlational and experimental studies have highlighted a potential role of glucocorticoids in determining telomere dynamics: increased glucocorticoids concentration (i.e. corticosterone and cortisol) were associated with a downregulation of telomerase activity or/and an accelerated rate of telomere shortening (Bauch et al., 2016; Choi et al., 2008; Haussmann et al., 2012; Quirici et al., 2016; Schultner et al., 2014; Young et al., 2016, 2016; but see Epel et al., 2010). Importantly, another investigation conducted in the same kittiwake population reported a negative relationship between baseline corticosterone levels and PFAS concentrations (Tartu et al., 2014). Even if underlying mechanisms are currently unclear, PFASs-induced lower circulating corticosterone levels might potentially result in relatively high telomerase activity in bone-marrow, and therefore in decreased rate of telomere shortening in highly contaminated kittiwakes.

Our study reported some telomere elongation between 2012 and 2014 in 4 kittiwakes. Interestingly, telomere elongation has already been associated with nutritional and climatic factors. Recently, Hoelzl et al. (2016) showed that food supplementation reduces telomere attrition and is even associated with telomere elongation in a wild mammal species, the dormouse (Glis glis). Similarly, Bebbington et al. (2016) reported an increased telomere length with high food availability in a small passerine, the Seychelles warbler (Acrocephalus sechellensis). Finally, a study conducted on the Black-tailed gull (Larus crassirostris) highlighted a potential positive effect of El Niño on telomere dynamics (Mizutani et al., 2013). 
Therefore, the lower rate of telomere shortenning in most PFASs contaminated kittiwakes highlighted in our study, in combination with good environmental conditions, could potentially explain why we observed telomere elongation in some kittiwakes.

We proposed here one possible underlying physiological mechanism, based on endocrine disruption, potentially explaining the reduced rate of telomere shortening in most PFASexposed kittiwakes. Although causality is difficult to assess in correlational studies, the relationships with telomere dynamics reported here may rely on ecological factors, rather than PFASs contamination. Besides, a study conducted in the same kittiwake colony reported a positive relationship between PFASs contamination and body condition in males (Tartu et al., 2014). This could suggest that the apparent positive effect of PFASs on telomere length maybe related to individual quality rather than to PFASs contamination. That is the reason why we included body condition in our analyses as a potential predictor of telomere length. However, body condition in 2012 was not related to absolute telomere length in 2012 and telomere dynamics. Indeed, telomere length does not fluctuate as fast as the body condition does, which is probably too labile compared to the slower rate of change of telomeres. Therefore, further ecological variables directly linked to feeding ecology (e.g. stable isotopes, protein amounts) of kittiwakes should be included as predictors of telomere length. Indeed, since food ingestion is the main route for PFASs exposure, the most contaminated kittiwakes could be the birds feeding at the highest trophic levels and are possibly the individuals of the highest quality. Another important point that deserves to be discussed is a potential confounding effect of age which is suggested to negatively affect telomere length (Haussmann and Vleck, 2002; Haussmann et al., 2003). However, this is particularly true for species with shorter lifespans which lose more telomeric repeats with age than species with longer lifespans (Haussmann et al., 2003). Indeed, in long-lived species, telomere loss appears to occur mainly early in life (i.e. between chick and adult stage) rather than during adulthood (Hall et al., 2004; Foote et al., 
2010), as is the case in other vertebrates (Frenck et al., 1998; Rufer et al., 1998; Zeichner et al., 1999; Friedrich et al., 2001). Since our study was conducted on breeding adults (i.e. at least 3e4 years old; Coulson, 2011) of a long-lived seabird and because we investigated telomere dynamics, with a longitudinal approach, we have some good reasons to think that age in our study is not a major factor influencing telomere length. However, relationships between age and PFASs in seabirds remains undocumented so far and thus, a potential confounding effect of age on PFAS concentrations here cannot be completely ruled out.

Despite some limitations and a moderate sample size, the positive relationship between PFASs contamination and telomere dynamics reported here could suggest a positive effect of PFASs exposure on telomeres and in fine, on survival rate of adult kittiwakes. This seems to be corroborated by findings from a recent study about PFASs and self-maintenance metabolism (Basal Metabolic Rate) conducted also on kittiwakes which supports the hypothesis that PFASs may stimulate self-maintenance mechanisms (Blévin et al., 2017). However, only capturemark-recapture (CMR) investigations would enable to confirm this statement and to fully validate our findings, future experimental investigations focusing on the effects of PFASs on telomere length should be carried out with a laboratory avian model.

\section{Conflict of interest}

The authors declare to have no conflicts of interest.

Acknowledgments: This project was supported by Institut Polaire Français (IPEV project 330 to O.Chastel) and by Agence National de la Recherche (ANR project PolarTop to O.Chastel) and by the Research Council of Norway (AVITOX project to J.O. Bustnes). We would like to thank the "Région Nouvelle Aquitaine" and the "Département des Deux-Sèvres" for equipment 
and also CPER ECONAT. This study was approved by the French and Norwegian Ethic committees and by the Governor of Svalbard. (FOTS ID 2012: 4226 and 2014: 6291). The authors thank the staff of NILU and L. Hanssen for PFASs analysis and G. Richard and A. Carravieri for statistical advices. 


\section{References}

Aas, C.B., Fuglei, E., Herzke, D., Yoccoz, N.G., Routti, H., 2014. Effect of body condition on tissue distribution of perfluoroalkyl substances (PFASs) in Arctic fox (Vulpes lagopus). Environmental Science \& Technology 48, 11654-11661.

Angelier, F., Vleck, C.M., Holberton, R.L., Marra, P.P., 2013. Telomere length, non-breeding habitat and return rate in male American redstarts. Functional Ecology 27, 342-350.

Asghar, M., Hasselquist, D., Hansson, B., Zehtindjiev, P., Westerdahl, H., Bensch, S., 2015. Hidden costs of infection: chronic malaria accelerates telomere degradation and senescence in wild birds. Science 347, 436-438.

Barrett, E.L., Burke, T.A., Hammers, M., Komdeur, J., Richardson, D.S., 2013. Telomere length and dynamics predict mortality in a wild longitudinal study. Molecular ecology 22, 249-259.

Bateson, M., 2016. Cumulative stress in research animals: Telomere attrition as a biomarker in a welfare context? BioEssays 38, 201-212.

Bauch, C., Becker, P.H., Verhulst, S., 2014. Within the genome, long telomeres are more informative than short telomeres with respect to fitness components in a long-lived seabird. Molecular ecology 23, 300-310.

Bauch, C., Riechert, J., Verhulst, S., Becker, P.H., 2016. Telomere length reflects reproductive effort indicated by corticosterone levels in a long-lived seabird. Molecular Ecology 25, 5785-5794.

Bize, P., Criscuolo, F., Metcalfe, N.B., Nasir, L., Monaghan, P., 2009. Telomere dynamics rather than age predict life expectancy in the wild. Proceedings of the Royal Society of London B: Biological Sciences 276, 1679-1683.

Blackburn, E.H., 2005. Telomeres and telomerase: their mechanisms of action and the effects of altering their functions. FEBS letters 579, 859-862.

Blackburn, E.H., 1991. Structure and function of telomeres. Nature 350, 569.

Blasco, M.A., 2007. Telomere length, stem cells and aging. Nature chemical biology 3, 640649.

Blévin, P., Angelier, F., Tartu, S., Ruault, S., Bustamante, P., Herzke, D., Moe, B., Bech, C., Gabrielsen, G.W., Bustnes, J.O., 2016. Exposure to oxychlordane is associated with shorter telomeres in arctic breeding kittiwakes. Science of the Total Environment 563, $125-130$.

Boonekamp, J.J., Mulder, G.A., Salomons, H.M., Dijkstra, C., Verhulst, S., 2014. Nestling telomere shortening, but not telomere length, reflects developmental stress and predicts survival in wild birds. Proceedings of the Royal Society of London B: Biological Sciences 281, 20133287.

Braune, B.M., Letcher, R.J., 2012. Perfluorinated sulfonate and carboxylate compounds in eggs of seabirds breeding in the Canadian Arctic: temporal trends (1975-2011) and interspecies comparison. Environmental Science \& Technology 47, 616-624.

Braune, B.M., Trudeau, S., Jeffrey, D.A., Mallory, M.L., 2011. Biomarker responses associated with halogenated organic contaminants in northern fulmars (Fulmarus glacialis) breeding in the Canadian Arctic. Environmental Pollution 159, 2891-2898.

Burnham, K.P., Anderson, D.R., 2004. Multimodel inference understanding AIC and BIC in model selection. Sociological Methods \& Research 33, 261-304.

Butt, C.M., Berger, U., Bossi, R., Tomy, G.T., 2010. Levels and trends of poly-and perfluorinated compounds in the arctic environment. Science of the Total Environment 408, 2936-2965. 
Butt, C.M., Mabury, S.A., Muir, D.C., Braune, B.M., 2007. Prevalence of long-chained perfluorinated carboxylates in seabirds from the Canadian Arctic between 1975 and 2004. Environmental Science \& Technology 41, 3521-3528.

Campisi, J., Kim, S., Lim, C.-S., Rubio, M., 2001. Cellular senescence, cancer and aging: the telomere connection. Experimental gerontology 36, 1619-1637.

Chatterjee, S., Hadi, A.S., 2015. Regression analysis by example. John Wiley \& Sons.

Choi, J., Fauce, S.R., Effros, R.B., 2008. Reduced telomerase activity in human T lymphocytes exposed to cortisol. Brain, behavior, and immunity 22, 600-605.

Conder, J.M., Hoke, R.A., Wolf, W. de, Russell, M.H., Buck, R.C., 2008. Are PFCAs bioaccumulative? A critical review and comparison with regulatory criteria and persistent lipophilic compounds. Environmental Science \& Technology 42, 995-1003.

Custer, C.M., Custer, T.W., Schoenfuss, H.L., Poganski, B.H., Solem, L., 2012. Exposure and effects of perfluoroalkyl compounds on tree swallows nesting at Lake Johanna in east central Minnesota, USA. Reproductive Toxicology 33, 556-562.

DeWitt, J.C., 2015. Toxicological effects of perfluoroalkyl and polyfluoroalkyl substances. Springer.TO BE COMPLETED

Ellis, D.A., Martin, J.W., De Silva, A.O., Mabury, S.A., Hurley, M.D., Sulbaek Andersen, M.P., Wallington, T.J., 2004. Degradation of fluorotelomer alcohols: a likely atmospheric source of perfluorinated carboxylic acids. Environmental Science \& Technology 38, 3316-3321.

Epel, E.S., Blackburn, E.H., Lin, J., Dhabhar, F.S., Adler, N.E., Morrow, J.D., Cawthon, R.M., 2004. Accelerated telomere shortening in response to life stress. Proceedings of the National Academy of Sciences of the United States of America 101, 17312-17315.

Epel, E.S., Lin, J., Dhabhar, F.S., Wolkowitz, O.M., Puterman, E., Karan, L., Blackburn, E.H., 2010. Dynamics of telomerase activity in response to acute psychological stress. Brain, Behavior, and Immunity 24, 531-539.

Erikstad, K.E., Sandvik, H., Reiertsen, T.K., Bustnes, J.O., Strøm, H., 2013. Persistent organic pollution in a high-Arctic top predator: sex-dependent thresholds in adult survival. Proceedings of the Royal Society of London B: Biological Sciences 280, 20131483.

Fairlie, J., Holland, R., Pilkington, J.G., Pemberton, J.M., Harrington, L., Nussey, D.H., 2016. Lifelong leukocyte telomere dynamics and survival in a free-living mammal. Aging Cell $15,140-148$.

Fang, S., Chen, X., Zhao, S., Zhang, Y., Jiang, W., Yang, L., Zhu, L., 2014. Trophic magnification and isomer fractionation of perfluoroalkyl substances in the food web of Taihu Lake, China. Environmental Science \& Technology 48, 2173-2182.

Findlay, G.M., DeFreitas, A.S.W., 1971. DDT movement from adipocyte to muscle cell during lipid utilization. Nature 229, 63-65.

Foote, C.G., Daunt, F., González-Solís, J., Nasir, L., Phillips, R.A., Monaghan, P., 2010. Individual state and survival prospects: age, sex, and telomere length in a long-lived seabird. Behavioral Ecology arq178.

Frenck, R.W., Blackburn, E.H., Shannon, K.M., 1998. The rate of telomere sequence loss in human leukocytes varies with age. Proceedings of the National Academy of Sciences 95, 5607-5610.

Fridolfsson, A.-K., Ellegren, H., 1999. A simple and universal method for molecular sexing of non-ratite birds. Journal of avian biology 116-121.

Friedrich, U., Schwab, M., Griese, E.-U., Fritz, P., Klotz, U., 2001. Telomeres in neonates: new insights in fetal hematopoiesis. Pediatric Research 49, 252-256.

Giesy, J.P., Kannan, K., 2001. Global distribution of perfluorooctane sulfonate in wildlife. Environmental Science \& Technology 35, 1339-1342. 
Goutte, A., Barbraud, C., Herzke, D., Bustamante, P., Angelier, F., Tartu, S., ClémentChastel, C., Moe, B., Bech, C., Gabrielsen, G.W., 2015. Survival rate and breeding outputs in a high Arctic seabird exposed to legacy persistent organic pollutants and mercury. Environmental Pollution 200, 1-9.

Graham, M.H., 2003. Confronting multicollinearity in ecological multiple regression. Ecology 84, 2809-2815.

Greider, C.W., Blackburn, E.H., 1985. Identification of a specific telomere terminal transferase activity in Tetrahymena extracts. Cell 43, 405-413.

Hall, M.E., Nasir, L., Daunt, F., Gault, E.A., Croxall, J.P., Wanless, S., Monaghan, P., 2004. Telomere loss in relation to age and early environment in long-lived birds. Proceedings of the Royal Society of London B: Biological Sciences 271, 1571-1576.

Harley, C.B., Futcher, A.B., Greider, C.W., 1990. Telomeres shorten during ageing of human fibroblasts. Nature 345, 458.

Haussmann, M.F., Longenecker, A.S., Marchetto, N.M., Juliano, S.A., Bowden, R.M., 2012. Embryonic exposure to corticosterone modifies the juvenile stress response, oxidative stress and telomere length. Proc. R. Soc. B. The Royal Society, pp. 1447-1456.

Haussmann, M.F., Winkler, D.W., Huntington, C.E., Nisbet, I.C., Vleck, C.M., 2007. Telomerase activity is maintained throughout the lifespan of long-lived birds. Experimental gerontology 42, 610-618.

Haussmann, M.F., Winkler, D.W., Vleck, C.M., 2005. Longer telomeres associated with higher survival in birds. Biology Letters 1, 212-214.

Heidinger, B.J., Blount, J.D., Boner, W., Griffiths, K., Metcalfe, N.B., Monaghan, P., 2012. Telomere length in early life predicts lifespan. Proceedings of the National Academy of Sciences 109, 1743-1748.

Heuvel, J.P.V., Kuslikis, B.I., Peterson, R.E., 1992. Covalent binding of perfluorinated fatty acids to proteins in the plasma, liver and testes of rats. Chemico-biological interactions $82,317-328$.

Jensen, A.A., Leffers, H., 2008. Emerging endocrine disrupters: perfluoroalkylated substances. International Journal of Andrology 31, 161-169.

Johnson, J.B., Omland, K.S., 2004. Model selection in ecology and evolution. Trends in Ecology \& Evolution 19, 101-108.

Kannan, K., 2011. Perfluoroalkyl and polyfluoroalkyl substances: current and future perspectives. Environmental Chemistry 8, 333-338.

Kannan, K., Tao, L., Sinclair, E., Pastva, S.D., Jude, D.J., Giesy, J.P., 2005. Perfluorinated compounds in aquatic organisms at various trophic levels in a Great Lakes food chain. Archives of Environmental Contamination and Toxicology 48, 559-566.

Kelly, B.C., Ikonomou, M.G., Blair, J.D., Surridge, B., Hoover, D., Grace, R., Gobas, F.A., 2009. Perfluoroalkyl contaminants in an Arctic marine food web: trophic magnification and wildlife exposure. Environmental Science \& Technology 43, 4037-4043.

Key, B.D., Howell, R.D., Criddle, C.S., 1997. Fluorinated organics in the biosphere. Environmental Science \& Technology 31, 2445-2454.

Kimura, M., Gazitt, Y., Cao, X., Zhao, X., Lansdorp, P.M., Aviv, A., 2010a. Synchrony of telomere length among hematopoietic cells. Experimental Hematology 38, 854-859.

Kimura, M., Stone, R.C., Hunt, S.C., Skurnick, J., Lu, X., Cao, X., Harley, C.B., Aviv, A., 2010b. Measurement of telomere length by the Southern blot analysis of terminal restriction fragment lengths. Nature protocols 5, 1596-1607.

Kissa, E., 2001. Fluorinated surfactants and repellents. CRC Press.

Kotrschal, A., Ilmonen, P., Penn, D.J., 2007. Stress impacts telomere dynamics. Biology Letters 3, 128-130. 
Lau, C., Anitole, K., Hodes, C., Lai, D., Pfahles-Hutchens, A., Seed, J., 2007. Perfluoroalkyl acids: a review of monitoring and toxicological findings. Toxicological Sciences 99, 366394.

Lessells, C.M., Boag, P.T., 1987. Unrepeatable repeatabilities: a common mistake. The Auk $116-121$.

Liu, Y., Wang, J., Fang, X., Zhang, H., Dai, J., 2011. The thyroid-disrupting effects of longterm perfluorononanoate exposure on zebrafish (Danio rerio). Ecotoxicology 20, 47-55.

Meillère, A., Brischoux, F., Parenteau, C., Angelier, F., 2015. Influence of urbanization on body size, condition, and physiology in an urban exploiter: a multi-component approach. PloS one 10, e0135685.

Mizutani, Y., Tomita, N., Niizuma, Y., Yoda, K., 2013. Environmental perturbations influence telomere dynamics in long-lived birds in their natural habitat. Biology Letters 9, 20130511.

Monaghan, P., Haussmann, M.F., 2006. Do telomere dynamics link lifestyle and lifespan? Trends in Ecology \& Evolution 21, 47-53.

Monitoring, A., 2004. AMAP Assessment 2002: Persistent Organic Pollutants in the Arctic.

Muir, D.C., de Wit, C.A., 2010. Trends of legacy and new persistent organic pollutants in the circumpolar arctic: overview, conclusions, and recommendations. Science of the Total Environment 408, 3044-3051.

Neter, J., Kutner, M.H., Nachtsheim, C.J., Wasserman, W., 1996. Applied linear statistical models. Irwin Chicago.

Nøst, T.H., Helgason, L.B., Harju, M., Heimstad, E.S., Gabrielsen, G.W., Jenssen, B.M., 2012. Halogenated organic contaminants and their correlations with circulating thyroid hormones in developing Arctic seabirds. Science of the Total Environment 414, 248-256.

Nussey, D.H., Baird, D., Barrett, E., Boner, W., Fairlie, J., Gemmell, N., Hartmann, N., Horn, T., Haussmann, M., Olsson, M., 2014. Measuring telomere length and telomere dynamics in evolutionary biology and ecology. Methods in Ecology and Evolution 5, 299-310.

Olovnikov, A.M., 1996. Telomeres, telomerase, and aging: origin of the theory. Experimental Gerontology 31, 443-448.

Prevedouros, K., Cousins, I.T., Buck, R.C., Korzeniowski, S.H., 2006. Sources, fate and transport of perfluorocarboxylates. Environmental Science \& Technology 40, 32-44.

Quirici, V., Guerrero, C.J., Krause, J.S., Wingfield, J.C., Vásquez, R.A., 2016. The relationship of telomere length to baseline corticosterone levels in nestlings of an altricial passerine bird in natural populations. Frontiers in Zoology 13, 1.

Rattiste, K., Klandorf, H., Urvik, J., Sepp, T., Asghar, M., Hasselquist, D., Cooey, C., Hõrak, P., 2015. Skin pentosidine and telomere length do not covary with age in a long-lived seabird. Biogerontology 16, 435-441.

Reichert, S., Criscuolo, F., Verinaud, E., Zahn, S., Massemin, S., 2013. Telomere length correlations among somatic tissues in adult zebra finches. PloS one 8, e81496.

Rotander, A., Kärrman, A., van Bavel, B., Polder, A., Rigét, F., Auðunsson, G.A., Víkingsson, G., Gabrielsen, G.W., Bloch, D., Dam, M., 2012. Increasing levels of long-chain perfluorocarboxylic acids (PFCAs) in Arctic and North Atlantic marine mammals, 19842009. Chemosphere 86, 278-285.

Salomons, H.M., Mulder, G. vd, van de Zande, L., Haussmann, M.F., Linskens, M.H., Verhulst, S., 2009a. Telomere shortening and survival in free-living corvids. Proceedings of the Royal Society of London B: Biological Sciences 276, 3157-3165.

Salomons, H.M., Mulder, G. vd, van de Zande, L., Haussmann, M.F., Linskens, M.H., Verhulst, S., 2009b. Telomere shortening and survival in free-living corvids. Proceedings of the Royal Society of London B: Biological Sciences 276, 3157-3165. 
Schultner, J., Moe, B., Chastel, O., Bech, C., Kitaysky, A.S., 2014. Migration and stress during reproduction govern telomere dynamics in a seabird. Biology Letters 10, 20130889.

Sedivy, J.M., 1998. Can ends justify the means?: telomeres and the mechanisms of replicative senescence and immortalization in mammalian cells. Proceedings of the National Academy of Sciences 95, 9078-9081.

Sletten, S., Bourgeon, S., Bårdsen, B.-J., Herzke, D., Criscuolo, F., Massemin, S., Zahn, S., Johnsen, T.V., Bustnes, J.O., 2016. Organohalogenated contaminants in white-tailed eagle (Haliaeetus albicilla) nestlings: An assessment of relationships to immunoglobulin levels, telomeres and oxidative stress. Science of the Total Environment 539, 337-349.

Stauffer, J., Panda, B., Eeva, T., Rainio, M., Ilmonen, P., 2017. Telomere damage and redox status alterations in free-living passerines exposed to metals. Science of the Total Environment 575, 841-848.

Sturkie, P.D., Griminger, P., 1976. Blood: physical characteristics, formed elements, hemoglobin, and coagulation, in: Avian Physiology. Springer, pp. 53-75.

Tartu, S., Bustamante, P., Angelier, F., Lendvai, A.Z., Moe, B., Blévin, P., Bech, C., Gabrielsen, G.W., Bustnes, J.O., Chastel, O., 2015a. Mercury exposure, stress and prolactin secretion in an Arctic seabird: an experimental study. Functional Ecology. TO BE COMPLETED

Tartu, S., Gabrielsen, G.W., Blévin, P., Ellis, H., Bustnes, J.O., Herzke, D., Chastel, O., 2014. Endocrine and fitness correlates of long-chain perfluorinated carboxylates exposure in Arctic breeding black-legged kittiwakes. Environmental Science \& Technology 48, 13504-13510.

Tartu, S., Goutte, A., Bustamante, P., Angelier, F., Moe, B., Clément-Chastel, C., Bech, C., Gabrielsen, G.W., Bustnes, J.O., Chastel, O., 2013. To breed or not to breed: endocrine response to mercury contamination by an Arctic seabird. Biology Letters 9, 20130317.

Tartu, S., Lendvai, Á.Z., Blévin, P., Herzke, D., Bustamante, P., Moe, B., Gabrielsen, G.W., Bustnes, J.O., Chastel, O., 2015b. Increased adrenal responsiveness and delayed hatching date in relation to polychlorinated biphenyl exposure in Arctic-breeding black-legged kittiwakes (Rissa tridactyla). General and Comparative Endocrinology 219, 165-172.

Tomy, G.T., Budakowski, W., Halldorson, T., Helm, P.A., Stern, G.A., Friesen, K., Pepper, K., Tittlemier, S.A., Fisk, A.T., 2004. Fluorinated organic compounds in an eastern Arctic marine food web. Environmental Science \& Technology 38, 6475-6481.

Vaziri, H., Dragowska, W., Allsopp, R.C., Thomas, T.E., Harley, C.B., Lansdorp, P.M., 1994. Evidence for a mitotic clock in human hematopoietic stem cells: loss of telomeric DNA with age. Proceedings of the National Academy of Sciences 91, 9857-9860.

Verreault, J., Houde, M., Gabrielsen, G.W., Berger, U., Haukås, M., Letcher, R.J., Muir, D.C., 2005. Perfluorinated alkyl substances in plasma, liver, brain, and eggs of glaucous gulls (Larus hyperboreus) from the Norwegian Arctic. Environmental Science \& Technology 39, 7439-7445.

Wania, F., 2003. Assessing the potential of persistent organic chemicals for long-range transport and accumulation in polar regions. Environmental Science \& Technology 37, 1344-1351.

Young, R.C., Barger, C.P., Dorresteijn, I., Haussmann, M.F., Kitaysky, A.S., 2016. Telomere length and environmental conditions predict stress levels but not parental investment in a long-lived seabird. Marine Ecology Progress Series 556, 251-259.

Young, R.C., Kitaysky, A.S., Haussmann, M.F., Descamps, S., Orben, R.A., Elliott, K.H., Gaston, A.J., 2013. Age, sex, and telomere dynamics in a long-lived seabird with malebiased parental care. PLoS One 8, e74931.

Zeichner, S.L., Palumbo, P., Feng, Y., Xiao, X., Gee, D., Sleasman, J., Goodenow, M., Biggar, R., Dimitrov, D., 1999. Rapid telomere shortening in children. Blood 93, 2824-2830. 
Zuur, A.F., Ieno, E.N., Elphick, C.S., 2010. A protocol for data exploration to avoid common statistical problems. Methods in Ecology and Evolution 1, 3-14.

Zuur, A.F., Ieno, E.N., Walker, N.J., Saveliev, A.A., Smith, G.M., 2009. Mixed effects models and extensions in ecology with R. Gail M, Krickeberg K, Samet JM, Tsiatis A, Wong W, editors. New York, NY: Spring Science and Business Media. 
Table 1. Plasma PFAS concentrations (ng/mL ww) according to sex in chick-rearing adult kittiwakes Rissa tridactyla from Kongsfjorden, Svalbard. Values are limits of detection (LODs) and mean concentrations \pm standard errors for male and female kittiwakes.

\begin{tabular}{|c|c|c|c|c|c|}
\hline & & Males $(n=22)$ & Females $(\mathrm{n}=$ & & \\
\hline & LODs & Mean \pm SE & Mean \pm SE & $F_{1,42}$ & $\overline{\text { P-value }}$ \\
\hline PFOSlin ${ }^{\text {a* }}$ & $70410^{-3}$ & $10.847 \pm 0.574$ & $8.922 \pm 0.676$ & 5.813 & 0.020 \\
\hline PFNA $^{\mathrm{b} *}$ & $40.910^{-3}$ & $1.210 \pm 0.099$ & $1.081 \pm 0.144$ & 1.923 & 0.173 \\
\hline $\mathrm{PFDcA}^{\mathrm{c}}$ & $61.910^{-3}$ & $2.193 \pm 0.120$ & $1.625 \pm 0.122$ & 11.000 & 0.002 \\
\hline PFUnA $^{\mathrm{d}}$ & $8310^{-3}$ & $12.110 \pm 0.641$ & $9.383 \pm 0.688$ & 8.403 & 0.006 \\
\hline $\mathrm{PFDoA}^{\mathrm{e} *}$ & $10910^{-3}$ & $2.541 \pm 0.136$ & $1.994 \pm 0.160$ & 8.748 & 0.005 \\
\hline $\operatorname{PFTrA}^{\mathrm{f} *}$ & $36010^{-3}$ & $11.618 \pm 1.410$ & $9.675 \pm 1.521$ & 1.574 & 0.217 \\
\hline
\end{tabular}

Significant p-values are in bold.

*Data were log-transformed to meet the assumption of the linear model

a PFOSlin: Perfluorooctane sulfonate

${ }^{b}$ PFNA: Perfluorononanoate

c PFDcA: Perfluorodecanoate

${ }^{\mathrm{d}}$ PFUnA: Perfluoroundecanoate

e PFDoA: Perfluorododecanoate

${ }^{f}$ PFTrA: Perfluorotridecanoate 
Table 2. AICc model ranking for telomere length in 2012 based on PFAS concentrations (PC1) and body condition in 2012 in chick-rearing adult kittiwakes Rissa tridactyla from Kongsfjorden, Svalbard. ( $\mathrm{n}=38,22$ males and 16 females). PFASs were measured in plasma.

\begin{tabular}{lccc}
\hline Models & AICc & $\Delta$ AICc $^{\mathbf{a}}$ & $\boldsymbol{W i}^{\mathbf{b}}$ \\
\hline Null & 99.57 & 0.00 & 0.35 \\
Sex & 99.82 & 0.26 & 0.30 \\
PC1 & 101.30 & 1.73 & 0.15 \\
Body condition & 101.81 & 2.24 & 0.11 \\
PC1 * Sex & 102.88 & 3.32 & 0.07 \\
Body condition * Sex & 104.83 & 5.26 & 0.02 \\
\hline $\begin{array}{l}\text { Abbreviations: AICc, bias-adjusted Akaike's Information Criteria values; } W i \text {, AICc weights. } \\
\text { a Scaled } \Delta \text { AICc; } \Delta \text { AICc }=0 \text { is interpreted as the best fit to the data among the models. } \\
\text { b Weight of evidence interpreted as a proportion. Weights across all models sum to } 1.00 .\end{array}$
\end{tabular}


Table 3. AICc model ranking for telomere dynamic between 2012 and 2014 based on PFAS concentrations (PC1) and body condition in 2012 in chick-rearing adult kittiwakes Rissa tridactyla from Kongsfjorden, Svalbard ( $\mathrm{n}=17,12$ males and 5 females). PFASs were measured in plasma.

\begin{tabular}{llll}
\hline Models & AICc & $\Delta \mathbf{A I C c}^{\mathbf{a}}$ & $\mathbf{W i}^{\mathbf{b}}$ \\
\hline PC1 & 28.81 & 0.00 & 0.70 \\
Null & 31.65 & 2.84 & 0.17 \\
PC1 * Sex & 33.99 & 5.19 & 0.05 \\
Sex & 34.44 & 5.63 & 0.04 \\
Body condition & 34.62 & 5.81 & 0.04 \\
Body condition * Sex & 41.77 & 12.96 & 0,00 \\
\hline
\end{tabular}

Abbreviations: AICc, bias-adjusted Akaike's Information Criteria values; $W i$, AICc weights.

${ }^{\text {a }}$ Scaled $\triangle \mathrm{AICc} ; \mathrm{AICc}=0$ is interpreted as the best fit to the data among the models.

${ }^{\mathrm{b}}$ Weight of evidence interpreted as a proportion. Weights across all models sum to 1.00 . 


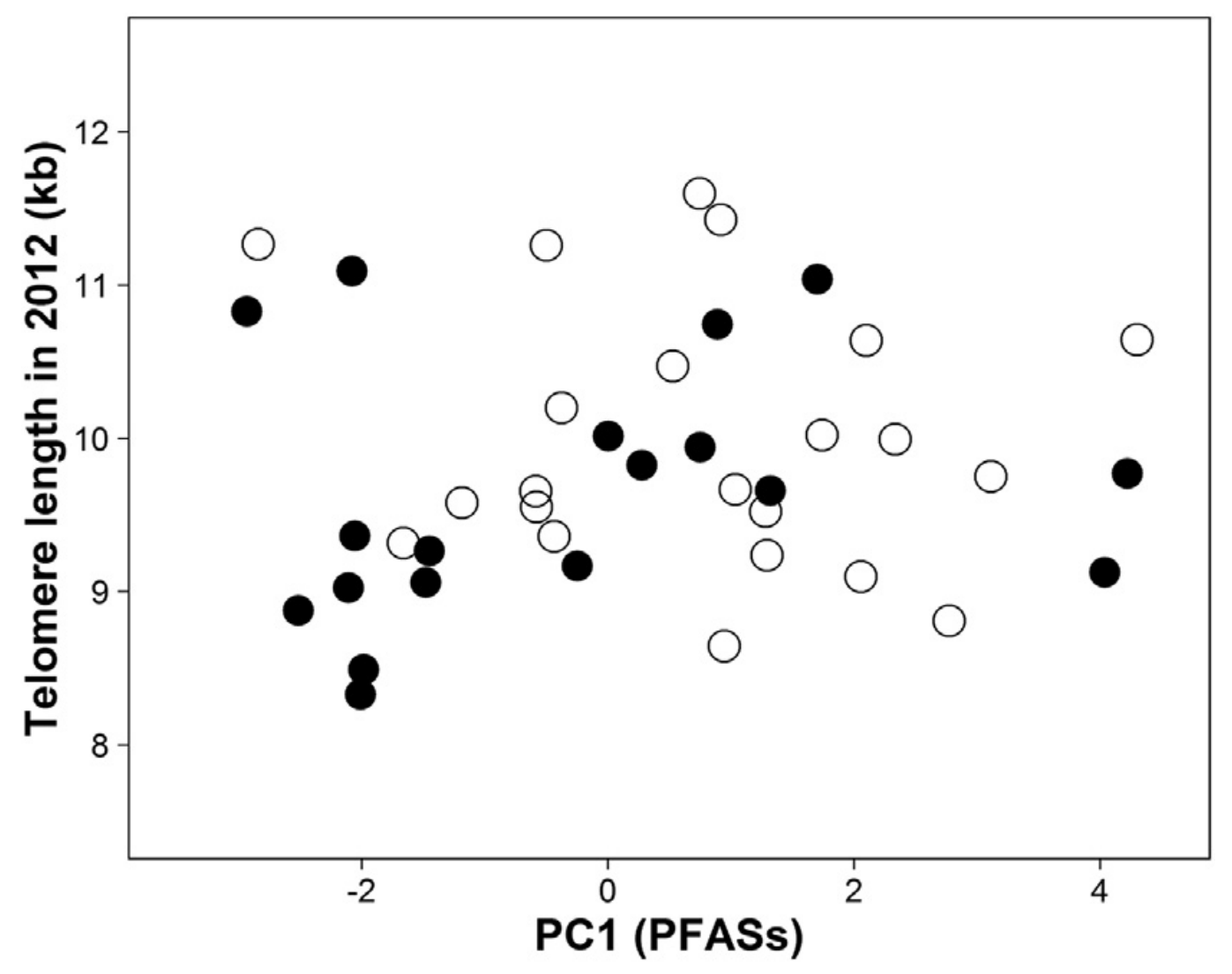

Fig. 1. Relationship between PC1 and absolute telomere length in 2012 in chick-rearing adult kittiwakes Rissa tridactyla from Kongsfjorden, Svalbard. The effect of PFAS concentrations in 2012 on telomere length in 2012 was tested with a linear model (slope: $\mathrm{a}=0.06, \mathrm{p}=0.443$ ). PC1 is mainly influenced by high concentrations of PFOSlin, PFDcA, PFUnA, PFDoA and to a minor extent PFNA and PFTrA. Males $(n=22)$ are represented with empty circles and females $(\mathrm{n}=16)$ with filled circles. 


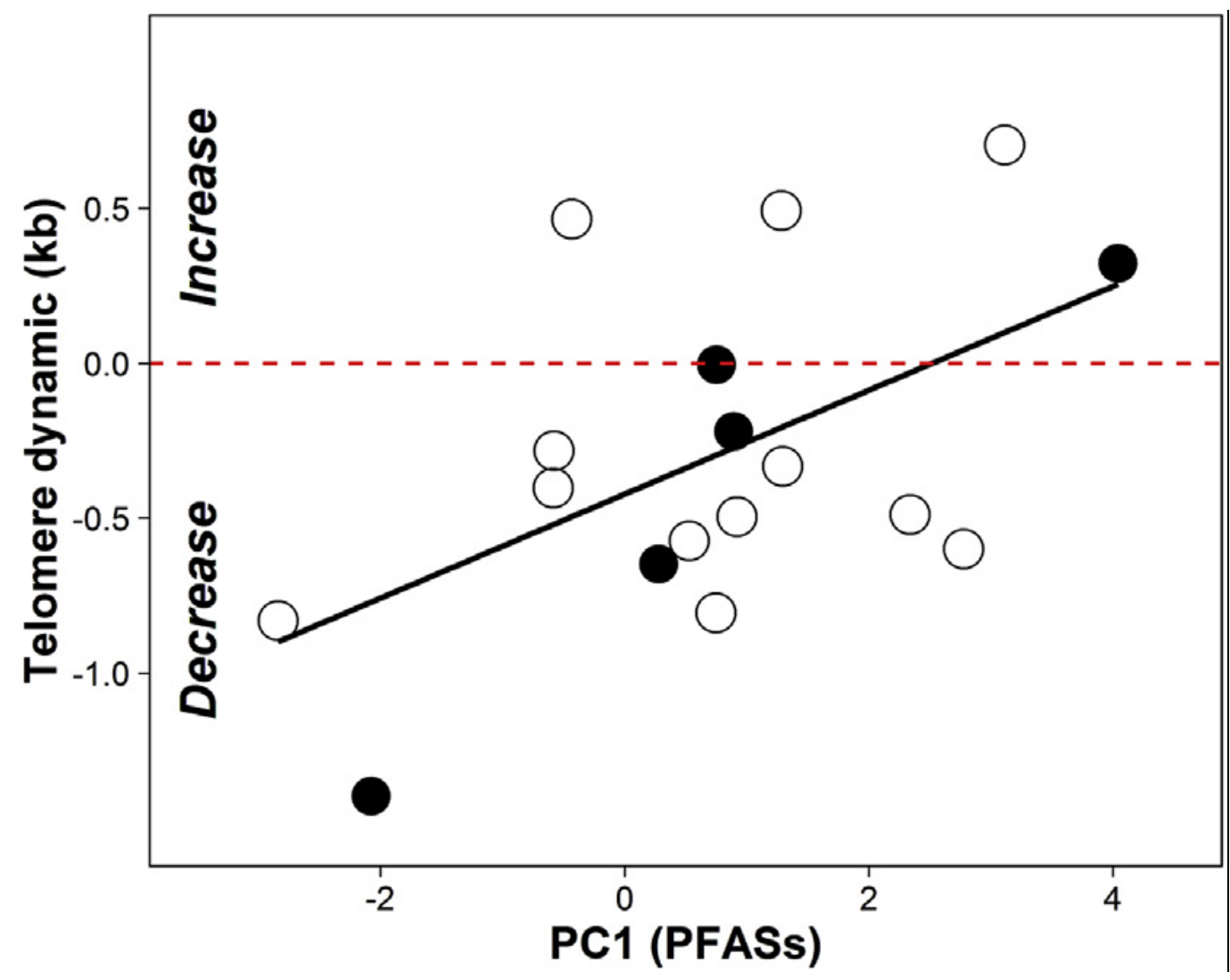

Fig. 2. Relationship between $\mathrm{PC} 1$ and telomere dynamics (the difference of telomere length between 2012 and 2014) in chick-rearing adult kittiwakes Rissa tridactyla from Kongsfjorden, Svalbard. The effect of PFASs in 2012 on telomere dynamics was tested with a linear model (slope: $\mathrm{a}=0.17, \mathrm{p}=0.026$ ). PC1 is mainly influenced by high concentrations of PFOSlin, PFDcA, PFUnA, PFDoA and to a minor extent PFNA and PFTrA. Males $(n=12)$ are represented with empty circles and females $(n=5)$ with filled circles. Individuals above red dashed line have increased telomere length whereas the ones bellow showed decreased telomere length between 2012 and 2014. (For interpretation of the references to colour in this figure legend, the reader is referred to the web version of this article.) 